\title{
Beneficial effects of a Coriolus versicolor- based vaginal gel on cervical epithelization, vaginal microbiota and vaginal health: a pilot study in asymptomatic women
}

\author{
Santiago Palacios ${ }^{1 *}$ (D) Fernando Losa ${ }^{2}$, Damián Dexeus ${ }^{3}$ and Javier Cortés ${ }^{4}$
}

\begin{abstract}
Background: To assess the effect of a 12-day treatment using a vaginal gel based on niosomes containing hyaluronic acid, B-glucan, alpha-glucan oligosaccharide, Coriolus versicolor, Asian centella, Azadirachta indica and Aloe vera on vaginal microbiota, cervical epithelization and vaginal health.

Methods: Open-label, prospective pilot study conducted in asymptomatic women in daily practice. Cervical epithelization was evaluated by colposcopy using an ectopy epithelization score (from 5: no ectopy to 1: severe ectopy and bleeding), vaginal microbiota using the VaginaStatus-Diagnostic test (Instiüt für Mikroökologie, Herborn, Germany) and further rated by the investigator using a 5-point Liker scale (from 5: normal to 1: very severe deterioration in which all evaluated species were altered), and vaginal health using the Vaginal Health Index.

Results: In 21 women, a positive effect to improve epithelization of the cervical mucosa, with a mean score of 4.42 at the final visit as compared to 3.09 at baseline $(P<0.0001)(43 \%$ improvement). In 10 women, there was a trend of improving of vaginal microbiota status, with a mean score of 4.0 at the final visit vs. 3.3 at baseline $(P=\mathrm{NS})(21.2 \%$ improvement). In 11 women, the Vaginal Health Index increased from 19.0 at baseline to 22.3 at the final visit $(P=0.007)$. The concentration of Lactobacillus spp. increased $54.5 \%$ of women and $\mathrm{pH}$ decreased from 4.32 to 4.09 .
\end{abstract}

Conclusions: These encouraging preliminary results provide the basis for designing a randomized controlled study, and for potential use in human papilloma virus infection.

Trial registration: ISRCTN77955077. Registration date: February 15, 2017. Retrospectively registered

Keywords: Vaginal gel, Coriolus versicolor, Niosomes, Cervical epithelization, Vaginal microbiota, Vaginal health

\section{Background}

The human female genital tract which includes the vaginal fluids present in the cervico-vaginal mucosa contain all essential elements for a number of functions, such as response against genital pathogens, re-epithelization of lesions and maintenance of general vaginal health. The vaginal ecosystem plays an important role in preventing urogenital infections, and alterations of this dynamic environment causes vaginal dysbacteriosis $[1,2]$. A healthy

\footnotetext{
* Correspondence: spalacios@institutopalacios.com

'Gynecology and Obstetrics Department, Instituto Palacios de Medicina y

Salud de la Mujer, C/Antonio Acuña 9, E-28009 Madrid, Spain

Full list of author information is available at the end of the article
}

vaginal ecosystem depends on a normal microbiota mainly consisting of Lactobacillus spp., a sufficient estrogendependent maturation of the vaginal epithelium and an intact local immunity [3]. The vaginal microbiota environment significantly affects the host's general state of health by acting as a biological barrier to infectious agents [4]. Preservation of other functions, such as hydration conditions of vaginal tissues, $\mathrm{pH}$, temperature, and characteristics of the cervical mucus have been also recognized to be important for the local activities of the innate and cell-mediated immune systems of vaginal epithelial cells $[5,6]$. 
To maintain a healthy vaginal ecosystem or to restore any disturbance, sufficient estrogen levels, an intact mature vaginal epithelium, and physiological Lactobacillus microbiota have been reported to be essential. It has been shown that topical combinations of lactobacilli and estrogens can be safely used in pre- and postmenopausal women for the restoration of the vaginal microbiota after anti-infective therapy, for treatment of symptomatic vaginal atrophy, and for abnormal vaginal flora therapy $[7,8]$. Local estrogen treatment restores the cytology $\mathrm{pH}$ and vascularity of the vagina, resulting in resolution of symptoms of vaginal atrophy $[9,10]$. Topical estrogen therapy for the treatment of atrophic vaginitis in postmenopausal women has been recommended by scientific societies and expert panel consensus [11, 12].

The concept of 'vaginal health' as the vaginal state in which the physiological conditions and the vaginal microenvironment and microbiota are not disrupted, has gained increasing interest in recent years and is also being extended to healthy women. Traditionally, natural products have been used for vaginal health, including probiotics, essential oils, propolis, lipid lubricans, pectins, medicinal plant extracts with phytoestroestrogenic activities and a variety of other extracts with primarily moisturizing effects [13-18].

Recently, a non-hormonal gel that acts as a moisturizer and lubricant because of strong hydrating properties, also enhancing and accelerating repair of atrophic or injured cervicovaginal mucosa has been approved in Spain as a medical device. The product is based on niosomes containing hyaluronic acid, ß-glucan, alpha-glucan oligosaccharide, Coriolus versicolor, Asian centella, Azadirachta indica (also known as Neem) and Aloe vera. Encapsulation in niosomes allows a more penetrating capability of the components, which have shown hydrating, repairing, anti-inflammatory and immunomodulatory effects as well as preserving the balance of vaginal microbiota [19-24].

A pilot study was designed to assess the clinical benefits of this Coriolus versicolor-based vaginal gel on epithelization of cervical lesions and to improve vaginal microbiota and vaginal health in asymptomatic healthy women.

\section{Methods}

\section{Design}

An open-label, non-comparative, prospective and pilot clinical study was conducted in two gynecology clinics from Madrid and Barcelona (Spain) in daily practice conditions. The objective of the study was to assess the effect of a Coriolus versicolor-based vaginal gel on the following parameters: a) epithelization of cervical lesions (reversion of cervical ectropion), b) composition of vaginal microbiota, and c) vaginal health. The studies were performed in accordance with the principles of the Declaration of Helsinki for the protection of human subjects, and oral informed consent was obtained from all participants. According to Spain regulations, ethics approval is not required for studies with the following characteristics: real life, pilot study, with a medical device (not a drug) class I already marketed and used within approved indication, and sponsored by the principal investigator and not by a private pharmaceutical company.

\section{Participants}

Women aged between 18 and 45 years old attending a routine gynecological visit, without signs and symptoms of vaginal disease and a normal Papanicolaou smear were included in the study. An epithelization score between 4 and 1 was also an inclusion criterion. Exclusion criteria included vaginal infections, use of vaginal products other than the investigational compound and being pregnant or breastfeeding. Women with history or concomitant diseases who were deemed to be ineligible by the investigator were also excluded from the study.

\section{Study procedures}

Women who agreed and met the inclusion criteria were instructed on the correct use of the vaginal gel (Palomacare ${ }^{\oplus}$, Procare Health, Castelldefels, Barcelona, Spain) according to the manufacturer's information leaflet supplied with the gel. In addition to the extract from Coriolus versicolor as the main agent, the gel contains nisosomes of hyaluronic acid (a moisturing agent), nisosomes de beta-glucan (an anti-inflammatory agent), Bioecolia ${ }^{\oplus}$ (a prebiotic agent), Centella asiatica (fitosomes ${ }^{\oplus}$ ) (a tissue regenerating agent), Azadirachta indica extract (Neem) (a re-epitelizing agent), and Aloe vera. It was recommended to use the medical device between periods, once a day and at bedtime for 12 consecutive days. There were no restrictions regarding sexual activity including the use of condoms. The use of douches or vaginal deodorants was not allowed. The vaginal gel was supplied to all women without cost for the total duration of treatment. Participants were visited at baseline (visit 1, inclusion in the study) and after 12 days of treatment (visit 2). In both visits the degree of epithelization, composition of vaginal microbiota, Lactobacillus spp. concentration, vaginal $\mathrm{pH}$, and the Vaginal Health Index were evaluated.

\section{Assessments}

The degree of epithelization of the cervical mucosa was evaluated by standard colposcopy and rated by the investigator using an ectopy epithelization score, where 5 was no ectopy, 4 : mild ( $<25 \%$ of the external os), 3: moderate $(25-50 \%$ of the external os), 2 : severe $(>50 \%$ of the external os) and 1: severe ectopy and bleeding. 
Table 1 Vaginal health index

\begin{tabular}{|c|c|c|c|c|c|}
\hline & 1 & 2 & 3 & 4 & 5 \\
\hline Elasticity & None & Poor & Fair & Good & Excellent \\
\hline $\begin{array}{l}\text { Fluid volume (pooling } \\
\text { of secretions) }\end{array}$ & None & $\begin{array}{l}\text { Scant amount, vault } \\
\text { not entirely covered }\end{array}$ & $\begin{array}{l}\text { Superficial amount, } \\
\text { vault entirely covered }\end{array}$ & $\begin{array}{l}\text { Moderate amount of dryness } \\
\text { (small areas of dryness on } \\
\text { cotton-tip applicator) }\end{array}$ & $\begin{array}{l}\text { Normal amount (fully saturates } \\
\text { on cotton-tip applicator) }\end{array}$ \\
\hline $\mathrm{pH}$ & $\geq 6.1$ & $5.6-6.0$ & $5.1-5.5$ & $4.7-5.0$ & $<4.6$ \\
\hline Epithelial integrity & $\begin{array}{l}\text { Petechiae noted } \\
\text { before contact }\end{array}$ & $\begin{array}{l}\text { Bleeds with light } \\
\text { contact }\end{array}$ & Bleeds with scraping & Not friable, thin epithelium & Normal \\
\hline Moisture (coating) & $\begin{array}{l}\text { None, surface } \\
\text { inflamed }\end{array}$ & $\begin{array}{l}\text { None, surface not } \\
\text { inflamed }\end{array}$ & Minimal & Moderate & Normal \\
\hline
\end{tabular}

Vaginal microbiota was evaluated using the VaginaStatusDiagnostic test (Instiüt für Mikroökologie, Herborn, Germany) [25] and further rated by the investigator using a 5-point Liker scale, in which 1 was very severe deterioration of vaginal microbiota (all evaluated species were altered); 2 : severe deterioration (detection of Candida spp. or Mycoplasma spp. or alterations in more than three species but not of all species); 3: moderate deterioration (alteration of three species but no Candida spp., Mycoplasma spp., Atopobium vaginae, Echerichia coli and Gardnerella vaginalis could be present); 4: mild deterioration (alteration of one or two species but no Candida spp., Mycoplasma spp., Atopobium vaginae, Echerichia coli and Gardnerella vaginalis could be present); and 5: normal. Lactobacillus spp. concentrations and $\mathrm{pH}$ were also measured.

The Vaginal Health Index was also assessed [26]. The Vaginal Health Index is a system used to evaluate vaginal elasticity, fluid volume, $\mathrm{pH}$, epithelial integrity, and moisture on a scale of 1 to 5 (Table 1). Both Vaginal Health
Index and vaginal microbiota were only assessed in 11 patients included in the Barcelona investigation site for logistic and financial reasons.

\section{Statistical analysis}

Because of the exploratory characteristics of the study, sample size calculation was not mandatory. Categorical variables are expressed as numbers and percentages, and quantitative variables as mean and standard deviation (SD). The Wilcoxon signed-rank test was used for the comparison of paired samples of continuous data. Data were analyzed with the Power Analysis and Sample Size software program, version 2011.

\section{Results}

\section{Epithelization of the cervix}

A total of 21 women with a mean age of 32.6 years (range 20-43 years) participated in evaluation of epithelization of the ectocervix. Treatment with the Coriolus

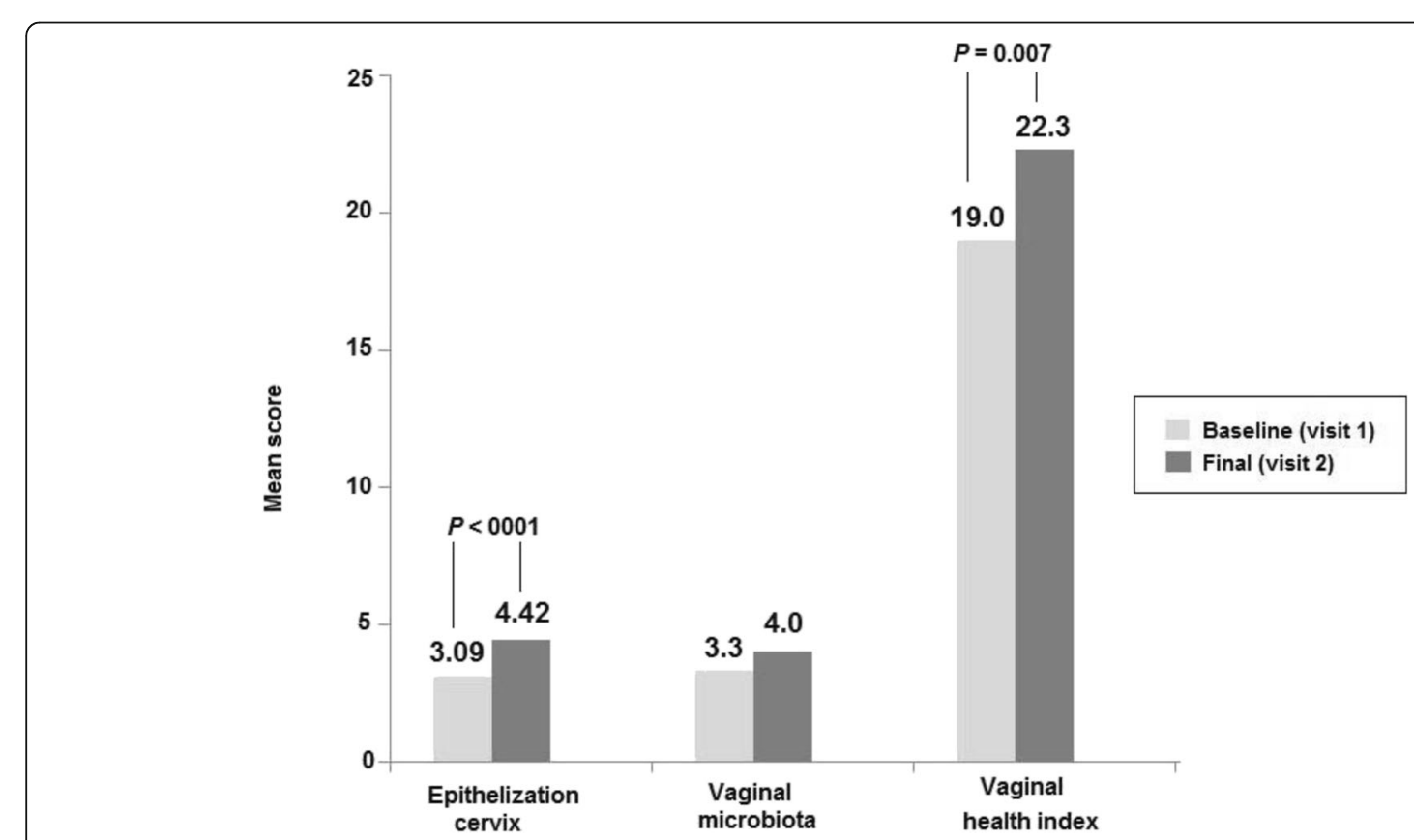

Fig. 1 Changes in the study parameters before and after 12-day treatment with a Coriolus versicolor-based vaginal gel 
Table 2 Results of colposcopy score

\begin{tabular}{|c|c|c|}
\hline \multirow[t]{2}{*}{ Patients } & \multicolumn{2}{|c|}{ Colposcopy epithelization score ${ }^{a}$} \\
\hline & Baseline (visit 1) & End of study (visit 2) \\
\hline 1 & 3 & 5 \\
\hline 2 & 3 & 4 \\
\hline 3 & 3 & 4 \\
\hline 4 & 1 & 3 \\
\hline 5 & 2 & 5 \\
\hline 6 & 3 & 3 \\
\hline 7 & 3 & 4 \\
\hline 8 & 2 & 4 \\
\hline 9 & 4 & 5 \\
\hline 10 & 3 & 4 \\
\hline 11 & 4 & 5 \\
\hline 12 & 4 & 5 \\
\hline 13 & 4 & 5 \\
\hline 14 & 3 & 5 \\
\hline 15 & 5 & 5 \\
\hline 16 & 4 & 5 \\
\hline 17 & 2 & 4 \\
\hline 18 & 4 & 5 \\
\hline 19 & 3 & 5 \\
\hline 20 & 2 & 4 \\
\hline 21 & 3 & 4 \\
\hline
\end{tabular}

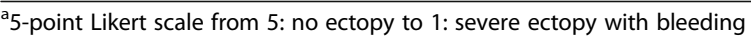

versicolor-based vaginal gel showed a positive effect to improve reepithelization of the cervical mucosa, with a mean score of 4.42 at the final visit as compared to 3.09 at baseline $(P<0.0001)$, and an overall improvement of $43 \%$ (Fig. 1). Also, at the end of the study, $95.3 \%$ of women showed an improvement in the epithelization degree, with a score of 5 observed in 11 women (52.4\%) (Table 2). Changes in colposcopic images before and after treatment are shown in Fig. 2.

\section{Vaginal microbiota}

Out of the 11 patients recruited, ten women aged between 20 and 43 years (mean age 32.8 years) were included in the assessment of vaginal microbiota (one exclusion due to sample manipulation error). At the baseline visit, 9 of 10 patients (90\%) showed some alterations in the vaginal microbiota (Gardnerella vaginalis, E. coli, Streptococcus spp. etc.) despite of being clinically asymptomatic. There was trend of improving of vaginal microbiota status, with a mean score of 4.0 at the final visit vs. 3.3 at baseline $(P=\mathrm{NS})$, and an improvement of $21.2 \%$ (Fig. 1). At the end of the study, 5 patients improved their vaginal status score with 4 of them reaching a 5-point score (normal status). One patient worsened and the remaining 4 showed no changes (Table 3 ).

\section{Vaginal health}

A total of 11 women aged between 25 and 43 years (mean age 32.6 years) were included in the assessment of vaginal health. There was a significant increase in the Vaginal Health Index from a mean of 19.0 at baseline to 22.3 at the final visit after 12 days of treatment $(P=$ 0.007) (Fig. 1). Also the concentration of Lactobacillus spp. increased in 6 patients (54.5\%) and no changes were observed in 1 . In the remaining 3 women, a decrease in Lactobacillus concentration was found. The mean vaginal $\mathrm{pH}$ showed a trend to decrease $(4.32$ vs. 4.09 , $P=$ NS) (Table 4).

Adverse effects due to using the vaginal gel were not recorded.

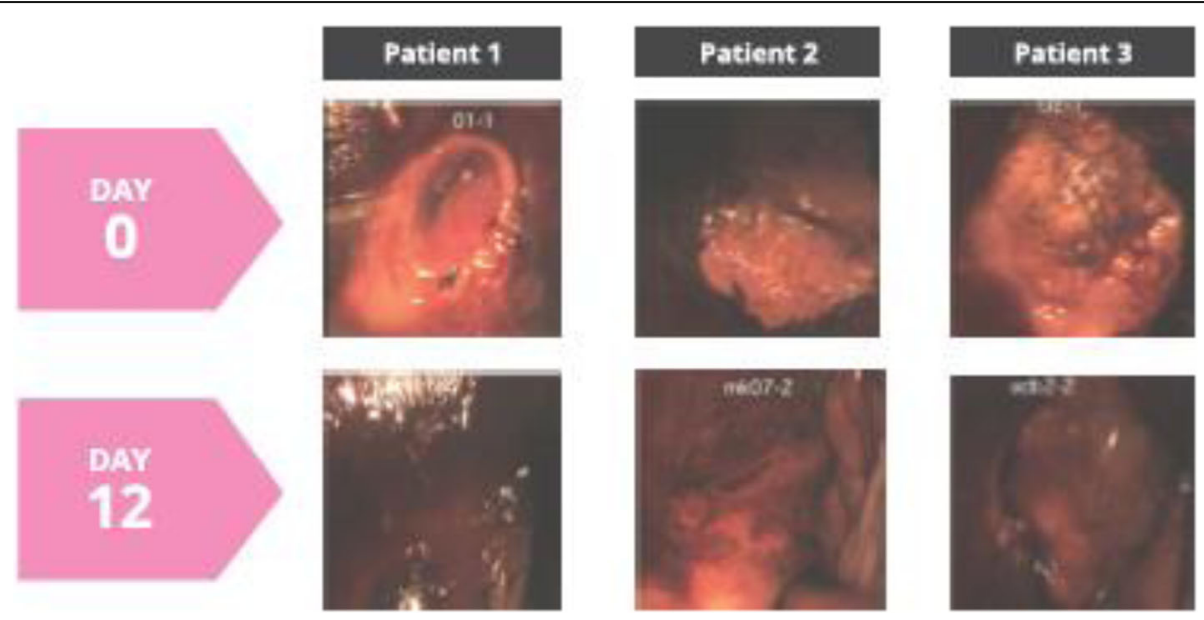

Fig. 2 Colposcopic images of three patients before and after applying test product 
Table 3 Results of vaginal microbiota

\begin{tabular}{lll}
\hline Patients & \multicolumn{2}{l}{ Vaginal microbiota score } \\
\cline { 2 - 3 } & Baseline (visit 1) & End of study (visit 2) \\
\hline 1 & 4 & 5 \\
2 & 3 & 3 \\
3 & 2 & 5 \\
4 & 4 & 5 \\
5 & 5 & 5 \\
6 & 2 & 4 \\
7 & 3 & 3 \\
8 & 4 & 2 \\
9 & 3 & 3 \\
10 & 3 & 5 \\
\hline
\end{tabular}

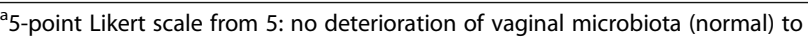
1 : very severe deterioration (alteration of all species evaluated)

\section{Discussion}

The present findings showing a clear beneficial effect of the Coriolus versicolor-based vaginal gel on epithelization of the ectocervix, vaginal microbiota and vaginal health, are highly encouraging for the design of a prospective randomized controlled study in order to confirm the results reported. If the multi-protective action of the vaginal gel observed in this pilot experience would be confirmed in a further randomized trial, clinical relevant effects in the mechanisms of entry and persistence of human papilloma virus (HPV) in the mucosal epithelium $[27,28]$ might be documented. Scientific evidence accumulated from virological, molecular, clinical and epidemiological studies has identified HPV as the primary etiological agent in cervical cancer [29-31].

In fact, the protection against viral aggression is based on three actions of the vaginal gel here described. Firstly, normalization of the vaginal microbiota. It is well known

Table 4 Changes in Lactobacillus spp. concentration and $\mathrm{pH}$

\begin{tabular}{llllll}
\hline Patients & \multicolumn{2}{l}{ Lactobacillus spp. } & & \multicolumn{2}{l}{ Vaginal pH } \\
\cline { 2 - 3 } $\begin{array}{l}\text { Baseline } \\
\text { (visit 1) }\end{array}$ & $\begin{array}{l}\text { End of study } \\
\text { (visit 2) }\end{array}$ & & $\begin{array}{l}\text { Baseline } \\
\text { (visit 1) }\end{array}$ & $\begin{array}{l}\text { End of study } \\
\text { (visit 2) }\end{array}$ \\
\hline 1 & $1 \times 10^{8}$ & $2 \times 10^{8}$ & 4.2 & 5.4 \\
2 & $3 \times 10^{8}$ & $5 \times 10^{8}$ & 4.8 & 4.2 \\
3 & $2 \times 10^{9}$ & $3 \times 10^{9}$ & 3.9 & 3.6 \\
4 & $5 \times 10^{8}$ & $5 \times 10^{8}$ & 4 & 3.8 \\
5 & $5 \times 10^{9}$ & $5 \times 10^{9}$ & 3.8 & 3.6 \\
6 & $<5 \times 10^{9}$ & $3 \times 10^{8}$ & 5.2 & 3.8 \\
7 & $5 \times 10^{8}$ & $<5 \times 10^{5}$ & 4.7 & 4.4 \\
9 & $1 \times 10^{8}$ & $3 \times 10^{8}$ & 4 & 4.2 \\
10 & $<5 \times 10^{5}$ & $5 \times 10^{5}$ & 4.2 & 4 \\
11 & $4 \times 10^{8}$ & $3 \times 10^{8}$ & 4 & 4 \\
\hline
\end{tabular}

Patient \#8 was excluded because of sampling handling error that bacterial vaginosis linked to an imbalance of vaginal ecosystem predisposes women to infection by HPV [32]. Palomacare ${ }^{\bullet}$ presents promising evidence of the correcting and stabilizing effects on vaginal microbiota. Secondly, the immunomodulatory properties. Polysaccharides and $\beta$ glucans from Coriolus versicolor, one of the components of the vaginal gel, have been shown to have antioxidant, immunomodulatory and anti-tumor properties [33, 34]. Moreover, extracts of Coriolus versicolor appear to be a lymphocyte mitogen by differentially enhancing the production of Th1-related cytokines [35]. A Th1 response has been shown to be important for clearance of HPV infection [36]. Thirdly, improvement of epithelization at the squamocolumnar junction in the ectocervix with subsequent reduction of mitotic activity may also decrease cell susceptibility to HPV infection [37].

The present results should be interpreted taking into account the pilot nature of the study, the absence of a control group and the short-term use of the product. Also, a comparison with previous studies is not presented as we report preliminary results of a pilot study with a new vaginal gel. However, these encouraging preliminary findings provide the basis for designing a randomized controlled study, and subsequently in the presence of confirmatory data, for potential use in HPV taking the advantages of easy and comfortable administration of the product.

\section{Conclusions}

In a pilot study conducted among asymptomatic women, the use of a vaginal gel based on Coriolus versicolor and other ingredients such as niosomes containing hyaluronic acid, ß-glucan, alpha-glucan oligosaccharide, Asian centella, Azadirachta indica and Aloe vera for 12 consecutive days showed positive effects toward improving vaginal microbiota, cervical epithelization and vaginal health. Further studies must be conducted to confirm these positive results, as well as to evaluate the potential use in human papilloma virus infection. Moreover, comparative studies with vaginal gels composed of estrogen and topical microbicides would be of interest.

\section{Abbreviation \\ HPV: Human papilloma virus}

\section{Acknowledgement}

We thank Marta Pulido, MD, who provided medical writing services on behalf of the authors.

Funding

Procare Health (Castelldefels, Barcelona, Spain) provided logistic support for the study but had no role in the design of the study and collection, analysis, and interpretation of data and in writing the manuscript

Availability of data and materials

Data supporting the findings can be provided by the authors upon request. 


\section{Authors' contributions}

SP participated in the conception and design of the study, data collection, data analysis and interpretation and helped to draft the manuscript. FL participated in the study design, data collection and interpretation of analysis. DD participated in the study design, data collection and interpretation of analysis. JC participated in the design of the study, data collection, data analysis, coordination of the study and drafted the manuscript. All authors read and approved the final manuscript.

\section{Competing interests}

The authors declare that they have no competing interests.

\section{Consent for publication}

Not applicable.

\section{Ethics approval and consent to participate}

The study was carried out in accordance with the principles of the Declaration of Helsinki. Oral informed consent was obtained from all participants. According to Spain regulations, ethics approval is not required for studies with the following characteristics: real life, pilot study, with a medical device (not a drug) class I already marketed and used within approved indication, and sponsored by the principal investigator and not by a private pharmaceutical company.

\section{Publisher's Note}

Springer Nature remains neutral with regard to jurisdictional claims in published maps and institutional affiliations.

\section{Author details}

${ }^{1}$ Gynecology and Obstetrics Department, Instituto Palacios de Medicina y Salud de la Mujer, C/Antonio Acuña 9, E-28009 Madrid, Spain. ${ }^{2}$ Gynecology and Obstetrics Department, Clínica Sagrada Familia, Barcelona, Spain. ${ }^{3}$ Gynecology and Obstetrics Department, SOMDEX-Clínica Tres Torres, Women's Health Institute, Barcelona, Spain. ${ }^{4}$ Senior Consultant on Gynecologic Oncology. Former President of the Spanish Association of Colposcopy and Cervical Pathology, Palma de Mallorca, Spain.

\section{Received: 24 September 2016 Accepted: 3 March 2017}

Published online: 16 March 2017

\section{References}

1. Witkin SS, Linhares IM, Giraldo P, Ledger WJ. An altered immunity hypothesis for the development of symptomatic bacterial vaginosis. Clin Infect Dis. 2007:44:554-7.

2. Redondo-Lopez V, Cook RL, Sobel JD. Emerging role of lactobacilli in the control and maintenance of the vaginal bacterial microflora. Rev Infect Dis. 1990;12:856-72.

3. Witkin SS, Linhares IM, Giraldo P. Bacterial flora of the female genital tract: function and immune regulation. Best Pract Res Clin Obstet Gynaecol. 2007; 21:347-54.

4. Kovachev SM. Obstetric and gynecological diseases and complications resulting from vaginal dysbacteriosis. Microb Ecol. 2014;68:173-84.

5. Ma B, Forney $L$, Ravel J. The vaginal microbiome: rethinking health and diseases. Ann Rev Microbiol. 2012;66:371-89.

6. Petrova MI, Lievens E, Malik S, Imholz N, Lebeer S. Lactobacillus species as biomarkers and agents that can promote various aspects of vaginal health Front Physiol. 2015:8:81. doi:10.3389/fphys.2015.00081.

7. Unlü C, Donders G. Use of lactobacilli and estriol combination in the treatment of disturbed vaginal ecosystem: a review. J Turk Ger Gynecol Assoc. 2011;12:239-46.

8. Donders G, Bellen G, Neven P, Grob P, Prasauskas V, Buchholz S, et al. Effect of ultra-low-dose estriol and lactobacilli vaginal tablets (Gynoflor ${ }^{\circledR}$ ) on inflammatory and infectious markers of the vaginal ecosystem in postmenopausal women with breast cancer on aromatase inhibitors. Eur J Clin Microbiol Infect Dis. 2015;34:2023-8.

9. Kokot-Kierepa M, Bartuzi A, Kulik-Rechberger B, Rechberger T. Local estrogen therapy-clinical implications-2012 update. Ginekol Pol. 2012;83:772-7.

10. Lindahl SH. Reviewing the options for local estrogen treatment of vaginal atrophy. Int J Womens Health. 2014;6:307-12.
11. Sánchez-Borrego R, Manubens M, Navarro MC, Cancelo MJ, Beltrán E, Duran M, et al. Position of the spanish menopause society regarding vaginal health care in postmenopausal women. Maturitas. 2014;78:146-50.

12. Management of symptomatic vulvovaginal atrophy. 2013 position statement of the North American menopause society. Menopause. 2013;20:888-902.

13. Borges S, Silva J, Teixeira P. The role of lactobacilli and probiotics in maintaining vaginal health. Arch Gynecol Obstet. 2014;289:479-89.

14. Sinha A, Ewies AA. Non-hormonal topical treatment of vulvovaginal atrophy: an up-to-date overview. Climateric. 2013;16:305-12.

15. Azimi $\mathrm{H}$, Fallah-Tafti M, Karimi-Darmiyan M, Abdollahi M. A comprehensive review of vaginitis phytotherapy. Pak J Biol Sci. 2011;14:960-6.

16. Juraskova I, Janvis S, Mok K, Peate M, Meiser B, Cheah BC, et al. The acceptability, feasibility, and efficacy (phase I/II study) of the OVERcome (olive Oil, vaginal exercise, and MoisturizeR) intervention to improve dyspareunia and alleviate sexual problems in women with breast cancer. J Sex Med. 2013;10:2549-58.

17. Caswell M, Kane M. Comparison of the moisturization efficacy of two vaginal moisturizers: pectin versus polycarbophil technologies. J Cosmet Sci. 2002;53:81-7.

18. Dover SE, Aroutcheva AA, Faro S, Chikindas ML. Natural antimicrobials and their role in vaginal health: a short review. Int J Probiotics Prebiotics. 2008;3:219-30.

19. Chu KK, Ho SS, Chow AH. Coriolus versicolor: a medicinal mushroom with promising immunotherapeutic values. J Clin Pharmacol. 2002:42:976-84.

20. Cui J, Chisti Y. Polysaccharides of coriolus versicolor: physiological activity, uses, and production. Biotechnol Adv. 2003:21:109-22.

21. Shukla S, Bharti AC, Hussain S, Mahata S, Hedau S, Kailash U, et al. Elimination of high-risk human papillomavirus type HPV16 infection by 'Praneem' polyherbal tablet in women with early cervical intraepithelial lesions. J Cancer Res Clin Oncol. 2009;135:1701-9.

22. Bylka W, Znajdek-Awiżeń P, Studzińska-Sroka E, Dańczak-Pazdrowska A, Brzezińska M. Centella asiatica in dermatology: an overview. Phytother Res. 2014;28:1117-24.

23. Chen J, Geng L, Song X, Li H, Giordan N, Liao Q. Evaluation of the efficacy and safety of hyaluronic acid vaginal gel to ease vaginal dryness: a multicenter, randomized, controlled, open-label, parallel-group, clinical trial. J Sex Med. 2013;10:1575-84

24. Radha MH, Laxmipriya NP. Evaluation of biological properties and clinical effectiveness of aloe Vera: a systematic review. J Tradit Complement Med. 2014;5:21-6.

25. VaginaStatus-Diagnostic test, Instiüt für Mikroökologie, Herborn, Germany. Available at. http://www.mikrooek.de. Accessed date 24 Feb 2016.

26. Bachmann GA, Notelovitz M, Kelly SJ, Thompson C. Long term nonhormonal treatment of vaginal dryness. Clin Pract Sexuality. 1992:8:3-8.

27. Horvath CA, Boulet GA, Renoux VM, Delvenne PO, Bogers JP. Mechanisms of cell entry by human papillomaviruses: an overview. Virol J. 2010;7:11. doi:10.1186/1743-422X-7-11.

28. Florin L, Sapp M, Spoden GA. Host-cell factors involved in papillomavirus entry. Med Microbiol Immunol. 2012;201:437-48

29. Woodman CB, Collins SI, Young LS. The natural history of cervical HPV infection: unresolved issues. Nat Rev Cancer. 2007;7:11-22.

30. Walboomers JM, Jacobs MV, Manos MM, Bosch FX, Kummer JA, Shah KV, et al. Human papillomavirus is a necessary cause of invasive cervical cancer worldwide. J Pathol. 1999;189:12-9.

31. Malik Al. The role of human papilloma virus (HPV) in the aetiology of cervical cancer. J Pak Med Assoc. 2005;55:553-8.

32. Gao W, Weng J, Gao Y, Chen X. Comparison of the vaginal microbiota diversity of women with and without human papillomavirus infection: a cross-sectional study. BMC Infect Dis. 2013:13:271. doi:10.1186/1471-2334-13-271.

33. Sun X, Sun Y, Zhang Q, Zhang H, Yang B, Wang Z, et al. Screening and comparison of antioxidant activities of polysaccharides from Coriolus versicolor. Int J Biol Macromol. 2014;69:12-9.

34. Wang Z, Dong B, Feng Z, Yu S, Bao Y, et al. A study on immunomodulatory mechanism of Polysaccharopeptide mediated by TLR4 signaling pathway. BMC Immunol. 2015;16:34. doi:10.1186/s12865-015-0100-5.

35. Ho CY, Lau CB, Kim CF, Leung KN, Fung KP, Tse TF, et al. Differential effect of Coriolus versicolor (Yunzhi) extract on cytokine production by murine lymphocytes in vitro. Int Immunopharmacol. 2004:4:1549-57.

36. Scott M, Nakagawa M, Moscicki AB. Cell-mediated immune response to human papillomavirus infection. Clin Diagn Lab Immunol. 2001:8:209-20.

37. Pyeon D, Pearce SM, Lank SM, Ahlquist P, Lambert PF. Establishment of human papillomavirus infection requires cell cycle progression. PLoS Pathog. 2009;5:e1000318. doi:10.1371/journal.ppat.1000318. 